\title{
PURCHASING BUSINESS IN THE CONDITIONS OF THE PANDEMIC CRISIS
}

\author{
Sandra Mrvica Mađarac ${ }^{1}$ (iD \\ Zvonimir Filipović ${ }^{2}$ (it) \\ Marko Eljuga ${ }^{3}$
}

DOI: https://doi.org/10.31410/ITEMA.2020.219

\begin{abstract}
Procurement is a function of the company that cares of everything about that is necessary for the realization of the goals of the business system and in particular it is very important for the successful operation of a trade company. Procurement is a function of the company and other business structures whose task is to supply the equipment, materials, services, products and energy needed to achieve goals of the business system. By pursuing the economic order quantities, decisions on expenditures and selection of the best suppliers we contribute to the business success. On the global level, companies are facing the impact and consequences of the COVID 19 pandemic, which also affects companies purchasing processes. In the paper are presented and analysed changes in the organization and functions of the purchasing business activities of the two companies as a consequence of the pandemic crisis.
\end{abstract}

Keywords: Purchasing business, Pandemic crisis, Supply, Organization, Company.

\section{INTRODUCTION}

7 he pandemic crisis has brought completely new and until now, unprecedented and unknown circumstances not only for all of us who participate in social life as individuals but also for all the participants in business processes who have faced a series of challenges they have not encountered so far. Restrictive measures brought by states to protect their population from infection have caused many difficulties when carrying out daily activities. Due to the COVID-19 pandemic, it is necessary to adapt social and economic life to the new conditions. Companies that are engaged in sales due to the reduction of social contacts and measures brought by the Civil Protection Headquarters of the Republic of Croatia had to change their business organization. On 24th April 2020, the Civil Protection Headquarters of the Republic of Croatia has issued a Decision stipulating the working hours and the way of work in the trade activity during the Coronavirus epidemic; all stores and all sales facilities were obliged to organize their work in compliance with the general anti-epidemic measures and special recommendations and instructions brought by the Croatian Institute of Public Health (Koronavirus, 15.06.2020). On 19th March 2020, the Civil Protection Headquarters of the Republic of Croatia has issued a Decision on measures to restrict social gatherings, work in trade, services and sporting and cultural events (Official Gazette, 32/2020), therefore suspending working of all shops except those listed in the decision.

College of Applied Sciences "Lavoslav Ružička” in Vukovar, Županijska 50, Vukovar, Croatia

PIK Vrbovec plus d.o.o., Gospodarska zona 20, Antunovac, Croatia

Agro - Honor d.o.o., Vrbaska 1c, Osijek, Croatia 
Procurement is a major part of the organizational and business process of any trading company. The paper presents the changes in the supply business in two trading companies during the course of the pandemic: one is engaged in the production and sale of food products, and the other in the sale of agricultural machinery.

\section{PROCUREMENT AS A FUNCTION OF TRADING COMPANY}

Procurement is function and activity of the company and other operating systems, which takes care of supplies, materials, equipment, services and energy that are necessary for the realization of the objectives of the business system. As an activity, it is extremely complex and important for the success of the company's business (Ferišak, 2006). Procurement tasks are:

- connecting companies with the market,

- procurement of means for production and its services in line with the production plan,

- organizing the process of circulating funds in reproduction,

- organizing work processes that ensure carrying out of individual procurements and the circulation of means of production in the previous phase of the production cycle (Karpati, 1975). By procurement in the narrower sense of the word is meant primarily running of operational activities in the process of acquiring the items of procurement. These are jobs that need to be performed on a daily basis in order to timely realize the defined needs and supply requirements of the business system for procurement facilities of appropriate quality, in the required quantity, at reasonable prices, with respect to deadlines, at a specific place and with the appropriate service. Operational functional procurement activities are as follows: examination and consolidation of procurement requests obtained from the preparation of work, development, warehouses, laboratories and other organizational units, observation and monitoring of the procurement market, making and setting inquiries to suppliers, receiving, examination and evaluation of suppliers' offers, negotiating with suppliers, selection of the most favourable offer and ordering, monitoring delivery deadlines and coordination of all direct connections with the suppliers, receiving and examination of the shipment, control of supplier's accounts, complaints due to inadequate fulfillment of the supplier's obligations, running records / files of procurement (Ferišak, 2002).

Procurement in a broader sense of the word encompasses strategic tasks on which depends the effect and profits of the business system. The tasks of procurement in a broader sense are to prepare the best possible use of procurement market opportunities, to positively influence to the production consumption and sales by defining types, forms of input structure when using the potential of suppliers and taking into account environmental protection, in order to better meet consumer demands, and to maximize the effects and profits of the business system (Ferišak, 2002). Marketing procurement significantly differs from the classic procurement system because here it does not run a typical "supplier-procurement" relationship, which is when the supplier motivates the customer to purchase certain goods or services, but the supplier and procurement party establish partnerships and thus facilitate the flow of procurement, that is, they realize short-term and long-term procurement tasks more efficiently and costeffectively (Ružić, 2002). The organizational structure of procurement deals with human and other resources, and refers to (Ferišak, 2002,317): division of tasks and procurement function, system of managerial and executive jobs and relations between them, system of obligations and authorities, system of work places responsibilities and system of communication between work places. When organizing procurement, it is necessary to adhere to certain principles, because non-compliance with them may bring many difficulties in business. These principles are: equal and fair division of labour among the employees, 
specialization of jobs within the service itself, standardization of goods procured, solutions to the problem of centralization-decentralization, principles of cooperation when doing business and proper assignment of authority and responsibility when performing affairs (Karpati, 1975, p. 42). By choosing the optimal form of organizational structure, it can be influenced on the business and business results of the company (Krpan et al., 2015). The very process of procurement is carried out in the following order (Peričić, Kozina, 2001): initiating the process of procurement, additional analysis of requirements for procurement and its approval, selection of the supplier and sending a request, invitation to tender, the selection of suppliers and sending orders and verification of goods from the suppliers. The procurement process is important for (Purchase Control, 2020): efficient purchasing process (not only intended for direct consumption), successful supplier relationship management, optimal supply chain management, rationalization of all stages of the procurement process, establishment of the management models of the business process.

\section{EXAMPLES OF BUSINESS PRACTICES OF PURCHASING ORGANIZATION DURING A PANDEMIC CRISIS}

Company $\mathrm{X}$ is a recognizable brand and market leader in Croatia in the production and sale of meat products, and its products are exported to foreign markets, with exports accounting for $10 \%$ of total annual sales. Since it is a manufacturing company that cannot perform its basic function of production without adequate supply of the raw materials, it is clear that the purchasing function is one of the most important functions of the company. Production results in the creation of added value, and in order for this added value to be competitive on the open market, it is necessary to ensure through the procurement function the highest quality of the raw material at the most competitive purchase price.

At the head of the company's procurement function is the procurement director who directly manages the procurement function and, according to the business organization, comes immediately below the company's director. The purchasing function of a company is roughly divided into two parts depending on the type of product being procured. The first group includes the procurement of raw materials that are directly necessary for the production process. The second group includes the procurement of everything else necessary for the smooth running of business processes in the company such as fixed assets, small inventory, etc. The procurement director manages the team of procurement managers for certain procurement groups, so the company has a procurement manager who cares for the purchasing of the raw materials and also the procurement manager who covers other group of procurements. In the procurement office they also have the procurement referents, which in coordination with their superior managers perform all the current activities related to the purchasing. It can be said that under normal circumstances before the pandemic, the procurement function took place almost routinely in accordance to the previously established schedules of activities. At the annual level, most of the procurement of key or basic raw materials necessary for the production is agreed upon. As this is the food industry, it is extremely important that the raw material for production is of exceptional quality and freshness, which in itself suggests that the preference is given to the domestic suppliers, i.e. the partners in the procurement process. The production process requires a certain time until the release of the finished product, so there is a need to conclude supply contracts for a longer period of time for at least a year, so that production can be planned in advance and proceed according to set plans and without production standstill. The aim of procurement is to supply raw materials of appropriate quality at the most competitive purchase price so that the final product itself will be as competitive as possible on the demanding domestic and foreign 
markets. Together with the coordination between the procurement director, procurement manager and procurement officers, the procurement itself is agreed and the course of the procurement process is controlled, depending on the scope of responsibilities of each level of employees working on the procurement service. The products that the company sells on the market have a seasonal character, which also directly affects the procurement function. The biggest support for the procurement of raw materials is provided by the domestic suppliers, but due to the increase in seasonal demand for certain groups of products it is impossible to meet the market demands without the procurement of raw materials from other countries - mostly often from the European Union. The food industry, even in normal circumstances, requires quick reactions and adjustments to market trends and needs, which requires exceptional flexibility from employees working in procurement and readiness to immediately address the challenges that have arisen before them.

A company that is engaged in the production of basic food products in the conditions of a pandemic crisis has found itself in great challenges. The population under the influence of psychosis that was caused by the set of limitations began to react irrationally; the panic caused an increase in demand for the Company X's products and there was a rapid decline of finished goods in stock. All of these new circumstances put before the procurement service tasks that had not been encountered so far. The company at a given time should provide enough products to supply the increased market demands, and at the same time the procurement should provide enough raw materials for the uninterrupted production. The employees who are not necessary present in the production process or who do not work directly in production are redirected to work from home through modern technologies that enable them to use mobile communications. The complete procurement service personnel were relocated to work from home in the present circumstances. Regardless of the work from home, the service had to react promptly and provide the allowed quantities of the necessary raw materials. The pandemic has caused numerous imbalances in the supply and demand for primarily food products, which has resulted in an uncontrolled rise of the prices of both final products and the raw materials that were needed for its production. Coordination with all other services in the company has moved to the virtual world through video links and similar advanced tools, but also communication with the suppliers has taken place by means of virtual meetings. Prior to the procurement, new tasks were set which comprehended the procurement of a sufficient amount of raw materials, regardless of the procurement price. It was in such crisis that the conditions were characterized by the increased in demand when all the shortcomings of our business environment had come to light. The domestic raw material base proved insufficient to meet the increased needs of the producers that were demanded by the market. Restrictions that were in force during the first wave of the pandemic with regards to the movement of goods and people in interstate traffic made it even more difficult to procure the raw materials from other countries. When working from home for all the procurement staff was required a much greater commitment to be able to complete all the necessary procurement processes than has occurred during normal times before the pandemic. The procurement has proven to be crucial for the company's survival on the market and for keeping the jobs for all of employees.

Company $\mathrm{Y}$ is specialized in retail and wholesale and service of small agricultural machines such as motor cultivators, chainsaws, lawn mowers, motor mowers (trimmers), water pumps, aggregates and other small machines. The procurement business of company $\mathrm{Y}$ is organized in such a way that the procurement of certain devices and spare parts takes place on a daily basis. As the company has organized both retail and wholesale, and since a relatively large number of customers regularly order and buy products, purchasing business must always be up to date. In the period before the pandemic crisis, the procurement business was organized in 
such a way that employees regularly collected orders from customers for the needs of service for their devices or to obtain the spare parts, which would be then forwarded to their warehouses to separate the items and to send them back to the company. Company Y orders a large amount of parts of devices and spare parts from companies operating within the Republic of Croatia, but it also orders and imports some goods directly from other countries, such as Germany, Italy, Serbia, Austria and other countries. Before the crisis, business with companies from the other countries has taken place without any problems, as well as business within the Republic of Croatia. The difference was exclusively in the duration of the time period spent for the delivery of the ordered goods. The crisis that began in March of this year has drastically changed the business of the company itself and businesses of all other companies with which the company cooperates. Namely, no one was prepared for what the crisis had caused. First of all, the delivery of ordered devices and spare parts and everything else started to be delayed, and apart from the fact that the delivery period has increased, an even bigger problem was that some deliveries were questionable and whether they would be realized at all. How the carriers were limited at the very beginning of the crisis to move to other countries, and the crisis itself has taken a big swing in the single countries (such as the case of Italy) - for the goods which have been ordered from those countries were put a lot of question marks (here, referring both to the production and distribution). Under these conditions, company $\mathrm{Y}$ had to change its current way of doing business and to adapt to the new situation. The first decision the company has made was to increase the stock of both the devices and the spare parts. Of course, this decision also had some negative consequences, because large stocks also result in the engagement of a more financial resources; it didn't do well in the crisis, but it was simply necessary to try to adjust the business. The second decision that has been taken - that it was necessary to clearly communicate this new way of doing business with the customers and service users. Namely, everyone needed to be explained why did exist a longer period of time for the delivery of devices from the service, but also for the delivery of spare parts and individual devices from the stores. Of course, this also had negative consequences, because it is understandable that some users did not show understanding, so in that case they gave up services. But since other companies had similar problems, finally there were not too many of discontented users. For the most part, customers and service users had an understanding and had remained loyal and they continued to buy items from the company Y. In addition to this, the company made several other adjustments in its business, all with the aim of realizing as much work as possible, and for them doing business and surviving on the market would not be put into question. At one point the crisis was showing signs of weakening and we all hoped it was about to end. Business began to return to normal and all the imposed measures slowly began to be abolished. So, business and movement of goods were allowed again to circulate as it was before the crisis. Unfortunately, again the situation has started to show up some negative trends related to the COVID 19 crisis. Yet again, there are introduced some limitations measures, but this time not as rigorous and businesses are more or less normally taking place, but again including a longer time interval. Uncertainty about how long this crisis will last has resulted for the company to focus exclusively on procuring those materials needed during this period, and is not willing to take any additional risks for the reason that no one can predict what tomorrow will bring. Purchasing business has normalized as much as possible, having larger stocks than before, but also, they offer narrower assortment. The company's goal is to provide its customers and service users with everything they need, to try to follow the trends, but the introduction and procurement of some new things has been currently put on hold. 


\section{CONCLUSION}

The COVID 19 pandemic crisis has been present for a long time and is causing great problems not only for economic entities, but also for all other activities. The consequences of the crisis, which is still going on day by day, are evident in the business operations of almost all companies. In these conditions, companies must find their way to organize their businesses as better as possible.

The main goal of the procurement business should be that procurement contributes as much as possible to the success of the company's business, and this can be achieved by using economies of scale and when choosing the right suppliers. Procurement tasks are to acquire materials and services of functionally appropriate quality, at the best price, in economical quantity, at the right time, from the most favourable sources, with high delivery service, when achieving the greatest possible protection of the environment and natural resources, with the least risks, with the lowest costs and with the good relationships with the suppliers. The procurement function in the company itself is extremely complex process even in the normal business conditions, and only in conditions such as the present pandemic crisis does the true importance of procurement in the organizational structure of each company come to light. The crisis has shown how extremely important it is to have a well-organized procurement service that will be able to perform all the tasks set before it even in difficult conditions, by the company's management. Developing partnerships with suppliers are needed that are not based on cooperation for only one delivery, but based on ongoing cooperation in which all participants in the supply process will be satisfied with the agreement that has proved to be crucial in time of the onset of the global pandemic crisis. It can be concluded that there is not much difference between procurement under normal circumstances and procurement during a pandemic crisis. Procurement is here to meet the needs of the company for the raw materials and other necessary resources that are necessary for business; it is only a question of how and with what employee engagement this can be achieved to be the most optimal solution for the company.

\section{REFERENCES}

Ferišak, V. (2006). Procurement - policy - strategy - organization - management. II updated edition, Zagreb, Croatia: Author's own edition.

Karpati, T. (1975). Procurement in the associated labour production organization, Osijek, Croatia: NIP Press.

Koronavirus, $\quad$ https://www.koronavirus.hr/odluka-o-radnom-vremenu-i-nacinu-rada-udjelatnosti-trgovine-za-vrijeme-trajanja-epidemije-koronavirusa/510, retrieved 19 June, 2020.

Krpan, Lj., Varga, D. \& Maršanić, R. (2015). Organizational structure of procurement business process. Technical Gazette, Vol. 9, No. 3, 327-336.

Official Gazette, 32/2020, Decision on measures restricting social gatherings, work in trade, service activities and holding sports and cultural events.

Peričić, G., Kozina, G. (2011). Significance of logistics procurement process in business system. Technical Gazette, Vol.5 No.1, 134-138.

Purchase Control, https://www.purchasecontrol.com/uk/blog/purchasing-process/, retrieved 27. September, 2020.

Ružić, D., Tomičić, Z. \& Turkalj, Ž. (2002). Exchange Relationships in Marketing. Osijek, Croatia: Faculty of Economics in Osijek. 